\title{
Wilms's tumour and aniridia: clinical and cytogenetic features
}

\author{
R S SHANNON, J R MANN, E HARPER, D G HARNDEN, J E N MORTEN, AND A HERBERT
}

Birmingham Children's Hospital and Department of Cancer Studies, University of Birmingham

SUMmARY A survey carried out to detect children with aniridia/Wilms's tumour syndrome identified 8 living and 3 dead children. The incidence of aniridia was found to be 1 in 43 among Wilms's tumour patients in the UK. The clinical features included complete bilaterial aniridia, cataracts, glaucoma, mental retardation, hyperkinesis, hypospadias, and undescended testes. A high incidence of bilateral tumours $(36 \%)$, male sex, presentation at a young age, and advanced maternal age appeared to be associated with the syndrome. The 8 living children each had a deletion on the short arm of chromosome 11. In contrast, although 2 patients with sporadic aniridia without Wilms's tumour had other malformations, neither had genitourinary anomalies, and the only additional problems in patients with familial aniridia were cataracts. Among 49 children with Wilms's tumour without aniridia only one had bilateral tumours. No chromosome abnormalities were detected in patients with familial aniridia, nor were they detected in patients with Wilms's tumour without aniridia or in those with sporadic aniridia without Wilms's tumour. While many infants with the Wilms's tumour/aniridia syndrome are clinically diagnosable at birth, chromosome analysis using the elongated chromosome method is especially valuable to confirm the diagnosis in girls with sporadic aniridia and in boys who lack the genitourinary malformations. The presence of an $11 \mathrm{p} 13$ deletion confirms the diagnosis of the Wilms's tumour/aniridia syndrome and indicates a very high risk for the development of Wilms's tumour.

The Wilms's tumour/aniridia syndrome was first described by Miller et al. ${ }^{1}$ who reported the association of mental retardation, microcephaly, bilateral aniridia, anomalies of the pinna, Wilms's tumour, and ambiguous genitalia in males. The syndrome is generally sporadic ${ }^{2}$ although familial occurrence has twice been described. ${ }^{3} 4$ Miller et al. ${ }^{1}$ reported 6 aniridia cases in $\mathbf{4 4 0}$ patients with Wilms's tumour (1 in 73) compared with 1 in 50000 births in the general population, and Pendergrass ${ }^{5}$ found 6 aniridia cases in 547 patients with Wilms's tumour (1 in 91).

Leck et al ${ }^{6}$ found 2 cases of aniridia in 190236 births surveyed in Birmingham (1 in 95000 ). Twothirds of aniridia cases are attributed to an autosomal dominant gene while the remaining cases are sporadic and thought to be due to a new mutation. ${ }^{7}$

In 1978 Riccardi et al. ${ }^{8}$ first described an interstitial deletion of the short arm of chromosome 11 in children with aniridia and Wilms's tumour. In this paper we report the incidence of the Wilms's tumour/aniridia syndrome among British patients and describe the clinical features and cytogenetic findings. Other patients with either Wilms's tumour or aniridia were also studied and the results compared with those of the Wilms's tumour/aniridia syndrome group.

\section{Methods}

Incidence. A survey was made of children with Wilms's tumour notified to the Medical Research Council's Working Party on Embryonal Tumours between 1969 and 1978. In addition the records of all 51 children treated for Wilms's tumour at Birmingham Children's Hospital between 1969 and 1978 were reviewed. Attempts were made through the records of the Childhood Cancer Research Group and paediatric colleagues to identify other children who had presented in the UK during the same years with Wilms's tumour or aniridia. Other children with sporadic and familial aniridia, with or without additional malformations but without Wilms's tumour, were identified through ophthalmological and paediatric colleagues.

Clinical studies performed. Information was 
obtained, and if possible confirmed, by interview and clinical examination (R S S). The data collected included mother's age at the birth of the child, details of congenital malformations, and family history.

Cytogenetic studies. Peripheral blood lymphocytes were set up using a standard whole blood technique stimulated with phytohaemagglutinin. Patients studied included the 8 living children with Wilms's tumour/aniridia syndrome and 10 of their parents, 3 children with sporadic aniridia, 2 mothers and 2 daughters with familial aniridia, and 6 children with unilateral Wilms's tumour who had no other congenital malformations. To achieve the high degree of resolution required to detect small interstitial deletions, every effort was made to produce elongated chromosome preparations. This was achieved by harvesting cultures after 46 hours and using a short (10 minutes) $0.002 \%$ colchicine treatment. This was found to give a reasonable yield of elongated prometaphase cells. Some cultures were also prepared using the technique of Yunis et al. ${ }^{9}$ which involves methotrexate synchronisation and precise timing of the harvesting of cells. Chromosome preparations were G-banded using the technique of Gallimore and Richardson. ${ }^{10}$

Other laboratory studies. As the deletion previously described in Wilms's tumour/aniridia patients was of the short arm of chromosome 11, attempts were made to identify other gene loci on this arm. Lactic dehydrogenase A (LDH A) is located at $11 \mathrm{p} 12 \cdot 03$ $12.08^{11} 1^{12}$ and therefore LDH A was studied in 4 of our Wilms's tumour/aniridia patients and in at least one parent of each. The enzyme was examined by starch gel electrophoresis. Quantitative assays of total LDH levels are unlikely to be informative in blood if LDH B is the predominant enzyme.

The gene loci for $\beta, \gamma$, and $\delta$ globin chains of haemoglobin are also believed to be situated on the short arm of chromosome 11, so the haemoglobin $F$ and A2 levels were measured using the methods of Betke et al. ${ }^{13}$ and Weatherall and Clegg, ${ }^{14}$ and haemoglobin analysis was made by starch gel electrophoresis.

\section{Results}

Clinical studies. Eight children with sporadic aniridia were identified from the records of 348 children with Wilms's tumour notified to the Medical Research Council's Working Party on Embryonal Tumours, giving an incidence of 1 in 43. These records included the 51 children treated for Wilms's tumour at Birmingham Children's Hospital during the same years of whom 2 had sporadic aniridia
(1 in 25). From the records of the Childhood Cancer Research Group a further 3 children were identified with Wilms's tumour and aniridia but for only one was further information available. Two further patients were located by personal referral. Thus we present information on a total of 11 children with Wilms's tumour/aniridia syndrome. Five children and 2 adults with sporadic or familial aniridia were studied too, and clinical details are shown in Table 1. Cases 3 and $8^{415}$ have been reported previously.

The mean age of the mothers of the 11 Wilms's tumour/aniridia children at the time of birth of these children was 30.5 (range 25-41) years. This was significantly older $(P=0.02)$ than the maternal age of other children with Wilms's tumour treated at Birmingham Children's Hospital (44 cases, mean maternal age 26.4 (range 17-36) years (data not available for 5 other mothers because of adoption or emigration).

Excluding the 2 Wilms's tumour/aniridia patients, malformations were present in $7(14 \%)$ of 49 Birmingham Children's Hospital Wilms's tumour children as follows: hemihypertrophy (2), hemihypertrophy and multiple pigmented naevi (1), Wiedemann-Beckwith syndrome (1), horseshoe kidney (1), neurofibromatosis (1), and spina bifida with hydrocephalus (1). Their clinical stages were stage I 26, II 9, III 5, IV 8, and V one (bilateral). In none was there a family history of Wilms's tumour or aniridia although the father of the child with Wiedemann-Beckwith syndrome had had macroglossia and a retroperitoneal neurilemmoma. This incidence of malformations is similar to that reported elsewhere. ${ }^{15}$ Twenty-seven of these children were boys and 22 girls.

The mean age at diagnosis of the Wilms's tumour(s) in the 11 Wilms's tumour/aniridia patients was 2.8 (range $0.6-5$ ) years and the mean age at diagnosis of the 49 other Wilms's tumour children treated in Birmingham Children's Hospital was 4.4 years (range 2 days -8.5 years).

Cytogenetic studies. The cytogenetic findings are summarised in Table 1 . No abnormalities were detected in the sporadic and familial aniridia subjects who did not have Wilms's tumour, nor were they detected in the Wilms's tumour patients without aniridia. However all 8 Wilms's tumour/ aniridia children had a deletion of the short arm of chromosome 11 (Figure). The extent of the deletion varied from patient to patient, but in 6 of these the G-negative band $11 \mathrm{p} 13$ was missing, while in case 7 it was much reduced in size. The rest of the karyotype was normal and no translocation of the deleted material was detected. For 4 of the Wilms's tumour/ aniridia patients both parents were examined and 
Wilms's tumour and aniridia: clinical and cytogenetic features

687

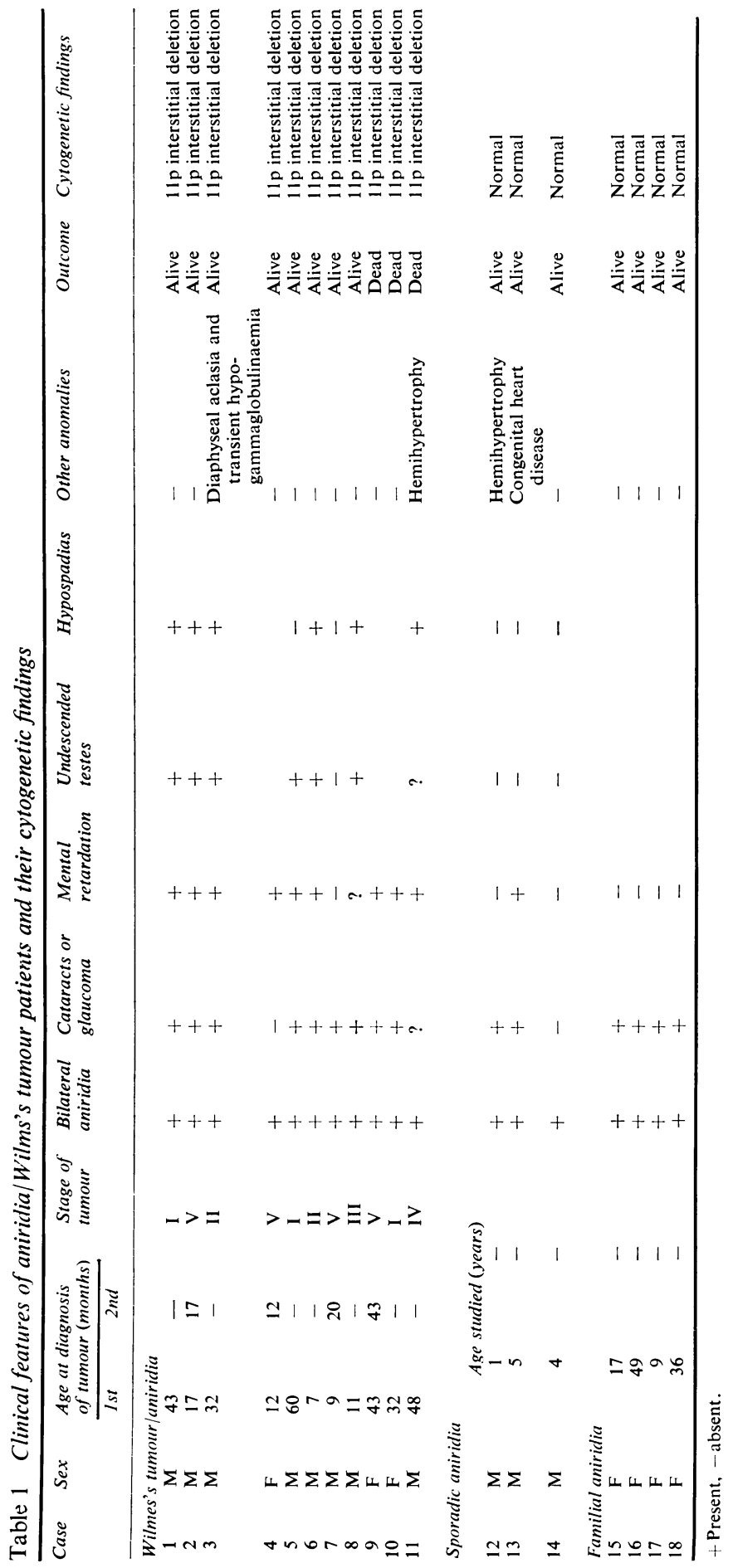




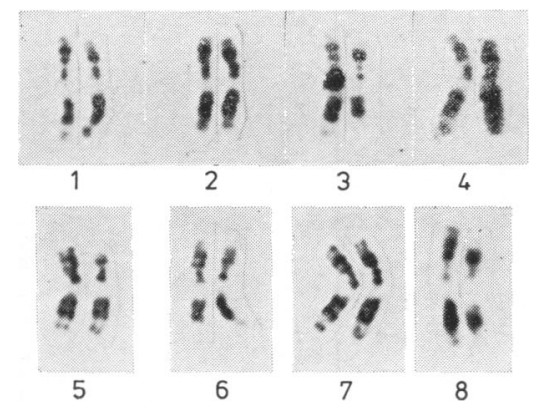

Case 1, deletion 11p12.08-11p14.02. Case 2, deletion 11p12.08$11 \mathrm{p} 14 \cdot 02$. Case 3 , deletion $11 \mathrm{p} 12 \cdot 08-11 \mathrm{p} 14 \cdot 02$. Case 4 , deletion $11 \mathrm{p} 12.08-11 \mathrm{p} 14.02$. Case 5, deletion $11 \mathrm{p} 12.02-11 \mathrm{p} 14.02$. Case 6, deletion 11p12.08-11p14.09. Case 7, deletion 11p13.01-11p13.09. Case 8, deletion 11p12.08-11p14.02.

Figure Pairs of chromosome 11 from the 8 patients studied. In each the deleted chromosome is on the right.

found to have normal chromosomes indicating that the deletions in their children were new mutations. For 2 other Wilms's tumour/aniridia patients only the mothers could be examined and their results were normal.

Total LDH levels were normal in all of the Wilms's tumour/aniridia children and parents tested. No obvious LDH gene dosage effect was detected by electrophoresis in 3 patients but Case 5 had a shift in the LDH A pattern compatible with a single dose of LDH A. Normal haemoglobin F and A2 levels and haemoglobin electrophoresis results were obtained in those patients studied.

\section{Discussion}

These studies further illustrate the clinical features of the Wilms's tumour/aniridia syndrome and confirm the presence of interstitial deletions on the short arm of chromosome 11. As in previous reports our patients have all shown complete bilateral aniridia and a high incidence of cataracts. Mental retardation, often with hyperkinesis, was nearly always present. Undescended testes and hypospadias were present in all but one of the boys, and one child had diaphyseal aclasia and transient hypogammaglobulinaemia of infancy.$^{15}$ Anomalies of the pinna and microcephaly not seen in our patients can also occur. In contrast, of the 3 children with sporadic aniridia without Wilms's tumour, although one had hemihypertrophy and another had cataracts, mental retardation, and congenital heart disease, none showed genitourinary malformations. Hemihypertrophy with or without aniridia is well known to be associated with Wilms's tumour, ${ }^{1}$ but no tumour has yet developed in Case 12 who is now aged 3.4 years.
The only additional problem in the familial aniridia patients was cataract.

Interesting features of the Wilms's tumour/ aniridia syndrome in our series include a tendency to older maternal age at birth of the affected child and a preponderance of males (8 out of 11, that is male: female ratio $2 \cdot 7: 1$ ). In contrast, the ratio of males: females in the Birmingham Children's Hospital Wilms's tumour series (excluding the aniridia cases) was $1 \cdot 2$, and was reported to be between 0.9 and 1.8 in other Wilms's tumour populations. ${ }^{16} \mathrm{~A}$ male preponderance in the Wilms's tumour/aniridia syndrome has been noted previously. ${ }^{17}$

As in other series ${ }^{12518}$ the tumours tended to present at a younger age in our patients with aniridia than in the general population of Wilms's tumour cases, but there was a wide range (7-60 months). The extremely high incidence of bilateral tumours $(36 \%)$ in our Wilms's tumour/aniridia patients contrasts strikingly with an incidence of $2 \%$ in the other Birmingham Children's Hospital Wilms's tumour cases and of $4.4 \%$ in a large general Wilms's tumour population. ${ }^{19}$ In a series of 11 children reported by Bond ${ }^{20}$ bilaterality was associated with older maternal age, a high incidence of malformations (including aniridia in one child), and young age at presentation of the tumours.

The overall incidence of aniridia in our British Wilms's tumour patients ( 1 in 43 ) appears higher than in the American series ${ }^{15}$ but may not differ significantly from the pooled estimate of their two and our series of 1 in 67.

All children with the Wilms's tumour/aniridia syndrome studied to date by the elongated chromosome method have had $11 \mathrm{p} 13$ deletions (Table 2). Thus, while many infants with the syndrome are clinically recognisable at birth, chromosome studies will be helpful in some babies with aniridia to identify those likely to develop Wilms's tumour, particularly girls, who do not show the genitourinary malformations, and cases of sporadic aniridia without other apparent defects. Our Case 7

Table 2 Reported cases of chromosomal abnormalities in aniridia/Wilms's tumour syndrome*

\begin{tabular}{clllll}
\hline Case & Sex & $\begin{array}{l}\text { Age at } \\
\text { diagnosis } \\
\text { (months) }\end{array}$ & $\begin{array}{l}\text { Bilateral } \\
\text { disease }\end{array}$ & $\begin{array}{l}\text { Mentally } \\
\text { retarded }\end{array}$ & $\begin{array}{l}\text { Genitourinary } \\
\text { anomalies }\end{array}$ \\
\hline 18 & M & 42 & None & Yes & Present \\
$223-26$ & F & 36 & None & Yes & None \\
311 & M & 19 & None & Yes & None \\
43 & M & 15 & Present & Yes & Present \\
527 & M & 10 & None & Yes & Present \\
627 & F & 12 & None & Yes & None \\
$7-1028$ & & &
\end{tabular}

*Excluding cases 1-622 described in this paper. 
was of special interest because his only malformations were bilateral aniridia and cataracts, yet he developed bilateral Wilms's tumours. It is probably relevant that in him the deletion was shorter than that present in any other Wilms's tumour/aniridia case we studied. At birth it would have been difficult clinically to determine that his risk of Wilms's tumour was greater than that for the other children (Cases 12-14) with sporadic aniridia. Thus chromosome analysis should prove to be particularly valuable in babies with sporadic aniridia who lack the other feature of the Wilms's tumour/aniridia syndrome, to predict those at risk of Wilms's tumour.

Although we confirmed the presence of interstitial deletions of the short arm of chromosome 11 in children with Wilms's tumour and aniridia, unlike Riccardi et al. ${ }^{8}$ we could not demonstrate this deletion in patients with aniridia alone, whether sporadic or familial, nor could we find it in those with Wilms's tumour alone. A deletion in the $11 \mathrm{p} 13$ region has also been reported in a girl with aniridia, cataracts, mental retardation, and gonadoblastoma. ${ }^{21}$

Familial occurrence of the Wilms's tumour/ aniridia syndrome has been described in a family in whom the proband showed a deletion of most of band $11 \mathrm{p} 13$ and of sub-band $11 \mathrm{p} 14.1$ and in whom the proband's mother and brother, who were both phenotypically normal, showed a balanced chromosomal rearrangement. ${ }^{3}$ Thus it seems clear that the $11 \mathrm{p} 13$ region contains a gene necessary for proper development of the iris and urogenital system and a locus which when absent predisposes to the development of malignancy, especially Wilms's tumour. However, since many cases of aniridia alone do not have deletion of $11 \mathrm{p} 13$, a deletion is not the only reason for this condition, which could be caused by point mutations at the same locus or by defects at other loci controlling development of the iris.

Although our studies are inconclusive, they may indicate that the locus for LDH is also situated in the $11 \mathrm{p} 13$ region, whereas the loci for the globin genes are not.

We thank Dr L Arthur, Dr S Bundey, Mr J J Corkery, Mr W Cochran, Dr M Friedman, Dr J S Lilleyman, Dr P $\mathbf{H}$ Morris Jones, Mr B O'Donnell, Dr J Pritchard, and Mr D G Young for permission to study their patients; Dr P H Morris Jones for access to the records of the patients notified to the Medical Research Council's Embryonal Tumour Working Party; Dr G J Draper for information from the records of the Childhood Cancer Research Group; $\mathrm{Mr} \mathrm{S}$ J Jerimiah, Dr P Rogers, and Dr P J L Cook, MRC Human Biochemical Genetics Unit, University College,
London, for the LDH A estimations; Dr K D Griffiths and the late Dr D N Raine, Biochemistry Department, Children's Hospital, Birmingham, for the haemoglobin analyses.

\section{References}

1 Miller R W, Fraumeni J F, Jr, Manning M D. Association of Wilms's tumor with aniridia, hemihypertrophy, and other congenital malformations. $N$ Engl J Med 1964; 270: 922-7.

2 Fraumeni J F, Jr, Glass A G. Wilms's tumor and congenital aniridia. JAMA 1968; 206: 825-8.

3 Yunis J J, Ramsay N K C. Familial occurrence of the aniridia-Wilms tumor syndrome with deletion $11 \mathrm{p} 13-14 \cdot 1$. J Pediatr 1980; 96: 1027-30.

4 Rangecroft L, O'Donnell B. Wilms' tumour and associated congenital anomalies. Ir J Med Sci 1980; 149: 191-3.

5 Pendergrass T W. Congenital anomalies in children with Wilms' tumor. A new survey. Cancer 1976; 37: 403-9.

6 Leck I, Record R G, McKeown T, Edwards J H. The incidence of malformations in Birmingham 1950-59. Teratology 1968; 1: 263-80.

7 Shaw M W, Falls H E, Neal J V. Congenital aniridia. Am J Hum Genet 1960; 12: 389-415.

8 Riccardi V M, Sujansky E, Smith A C, Francke U. Chromosomal imbalance in the aniridia-Wilms' tumor association: 11p interstitial deletion. Pediatrics 1978; 61 : 604-10.

9 Yunis J J, Sawyer J R, Ball D W. The characterization of high resolution G-banded chromosomes of man. Chromosoma 1978; 67: 293-307.

10 Gallimore P H, Richardson C R. An improved banding technique exemplified in the karyotype analysis of two strains of rat. Chromosoma $1973 ; 41$ : 259-63.

11 Francke U, George D L, Brown M G, Riccardi V M. Gene dose effect: intraband mapping of the LDH A locus using cells from four individuals with different interstitial deletions of $11 \mathrm{p}$. Cytogenet Cell Genet 1977; 19: 197-207.

12 Boone C, Chen T R, Ruddle F H. Assignment of three human genes to chromosomes (LDH A to 11, TK to 17, and 1.DH to 20) and evidence for translocation between human and mouse chromosomes in somatic cell hybrids (thymidine kinase-lactate dehydrogenase A-isocitrate dehydrogenase-C-11, E-17, and F-20). Proc Natl Acad Sci USA 1972; 69: 510-4.

13 Betke K, Marti H R, Schlicht I. Estimation of small percentages of foetal haemoglobin. Nature 1959; 184: 1877-8.

14 Weatherall D J, Clegg J B. The thalassaemia syndrome. Oxford: Blackwell, 1972.

15 Evans D I K, Holzel A. Wilms' aniridia syndrome with transient hypogammaglobulinaemia in infancy. Arch Dis Child 1973; 48: 645-6.

16 Sutow W W, Hussey D H, Ayala A G, Sullivan M P, Wilms' tumor. In: Sutow W W, Vietti T J, Fernbach D J, eds Clinical pediatric oncology. St Louis: Mosby, 1977: 538-68.

17 Miller R W. Relation between cancer and congenital defects in man. $N$ Engl J Med 1966; 275 : 87-93.

18 Pilling G P. Wilms' tumor in seven children with congenital aniridia. J Pediatr Surg 1975; 10: 87-96.

19 Ragab A H, Vietti T J, Crist W, Perez C, McAllister W. Bilateral Wilms' tumor. A review. Cancer 1972; 30: 983-8.

20 Bond V J. Bilateral Wilms' tumor. Lancet 1975; ii : 482-4.

21 Andersen S R, Geertinger P, Larsen H W, Mikkelsen M, Parving A, Vestermark S, Warburg M. Aniridia, cataract, 
and gonadoblastoma in a mentally retarded girl with deletion of chromosome 11. Ophthalmologica 1978; 176: 171-7.

22 Shannon R S, Harnden D G, Harper E, McIntosh L P, Mann J R. Growth and genetic studies on children with Wilms' tumours (abstract). In the proceedings of the Eleventh Meeting of the International Society of Paediatric Oncology, Lisbon 1979.

${ }^{23}$ Cotlier E, Rose M, Moel S A. Aniridia, cataracts, and Wilms' tumor in monozygous twins. Am J Ophthalmol 1978; 86: 129-32.

24 Maurer H S, Pendergrass T W, Borges W, Honig G R. The role of genetic factors in the etiology of Wilms' tumor. Cancer 1979; 43: 205-8.

25 Francke U, Riccardi V M, Hittner H M, Borges W. Interstitial del(11p) as a cause of the aniridia/Wilms' tumor association: band localization and a heritable basis (abstract). Am Soc Hum Genet 1978; 30: 81 A.

${ }^{26}$ Riccardi V M, Hittner $\mathbf{H ~ M}$, Francke U, Yunis J J,
Ledbetter D, Borges W. The aniridia-Wilms' tumor association: the critical role of chromosome band $11 \mathrm{p} 13$. Cancer Genet Cytogenet 1980; 2: 131-7.

27 Slater R M, Bleeker-Wagermakers E M. Aniridia, Wilms' tumour, and chromosome No 11 (abstract). In the proceedings of the Twelfth Meeting of the International Society of Paediatric Oncology, Budapest 1980.

28 Bader J L, Li F P, Gerald P S, et al. 11p chromosome deletion in 4 patients with aniridia and Wilms' tumour. (abstract). Proc Am Acad Clin Res 1979; 20-21 : A850.

29 Culliton B J, Waterfall K. Symposium on genetics. $\mathrm{Br}$ Med J 1979; ii: 1059-60.

Correspondence to Dr Rosemary Shannon, Department of Paediatrics, Leicester Royal Infirmary, Leicester LE1 5WW.

Received 19 May 1982

\section{The following articles will appear in future issues of this journal:}

Developmental and neurological progress of preterm infants with intraventricular haemorrhage and ventricular dilatation P Palmer, L M S Dubowitz, M I Levene, and V Dubowitz

Tuberculosis in children in a national survey of notifications in England and Wales, 1978-79

Report from the Medical Research Council Tuberculosis and Chest Diseases Unit

Food intolerance and food allergy in children: a review of 68 cases

A M B Minford, A MacDonald, and J M Littlewood

Screening for cystic fibrosis

$J A$ Dodge and H C Ryley

Retinopathy of prematurity: oxygen dogma challenged

$W$ A Silverman 